\title{
TEM observation of rod-shaped precipitates in Al-Mg-Ge Alloy
}

\author{
Teruyoshi Munekata ${ }^{1}$, Kenji Matsuda $^{2}$, Yasuhiro Uetani ${ }^{3}$, Susumu Ikeno $^{2}$ \\ ${ }^{1}$ Graduate student, Toyama University, 3190, Gofuku, Toyama, 930-8555, Japan \\ ${ }^{2}$ Department of System Engineering for Materials and Life Science, Faculty of Engineering, Toyama University, \\ 3190, Gofuku, Toyama, 930-8555, Japan \\ ${ }^{3}$ Reserch Institute for technology, Toyama Prefectural University, 5180, Kurokawa, Kosugi, Imizu-gun, Toyama, \\ 939-0398, Japan
}

\section{Introduction}

A lot of studies have been done on intermediate phase in Al-Mg-Si alloys about crystal structure and chemical composition [1-3]. The determination of atomic position in the unit cell of the precipitate is difficult because of the similar atomic weight and atomic scattering factor between $\mathrm{Si}$ and $\mathrm{Mg}$. As a result, Ge, which is in the homologous element as $\mathrm{Si}$ in the periodic table, but with a heavier atomic weight, was used to replace $\mathrm{Si}$ in Al-Mg-Si alloys. Al-Mg-Ge alloy has been reported that similar precipitates were formed as in Al-Mg-Si alloy [4]. However, comparing Al-Mg-Si alloy and Al-Mg-Ge alloy using high resolution TEM and selected area diffraction pattern have not been well investigated yet. The present study has been on comparing cross section of rod-shaped precipitates in Al-Mg-Si and Al-Mg-Ge alloys using HRTEM and SADP technique.

\section{Experimental}

The Al-1.0mass $\% \mathrm{Mg}_{2} \mathrm{Ge}$ alloy was used for the present study. The ingot was hot-and cold-rolled to a sheet of $0.2 \mathrm{~mm}$ thickness. This sheet was solution heat-treated at $873 \mathrm{~K}$ for $3.6 \mathrm{ks}$ and quenched in chilled water at $273 \mathrm{~K}$. The aging condition was performed at $523 \mathrm{~K}$. For TEM, specimen was prepared by electrolytic polishing using 10 percent perchloric acid and 90 percent ethanol. TEM (Topcon, 002B) was operated at 120kV. Jeol 4010T was also used for high-resolution observation at 400kV.

\section{Result}

Fig.1 shows TEM image of this alloy aged at $523 \mathrm{~K}$ for $12 \mathrm{ks}$. Rod-shaped precipitates were found to have the directions aligning along [100] and [010] directions of the matrix as the same as precipitates in Al-Mg-Si alloy. Cross section of rod-shaped precipitates were investigated by HRTEM. Fig.2 shows hexagonal network of $0.72 \mathrm{~nm}$. This is the similar to $\beta$ phase which is typical metastable phase in Al-Mg-Si alloy. Precipitates which have rectangular network of $0.35 \mathrm{~nm}$ and $0.68 \mathrm{~nm}$ also found in the same sample (Fig.3). This precipitates is quite similar to the type-A precipitates that is one of typical precipitate in $\mathrm{Al}-1.0 \mathrm{mass} \% \mathrm{Mg}_{2} \mathrm{Si}-0.4 \mathrm{mass} \% \mathrm{Si}$ alloy (excess Si type). These results were also taken from SADPs.

\section{Conclusion}

A rod-shaped precipitate in Al-Mg-Ge alloy was found to have the directions along [100], [010] and [001] directions of the matrix and it was similar to a precipitate in Al-Mg-Si alloy. Its cross section of rod-shaped precipitates were found that similar to $\beta^{\prime}$ phase or type-A precipitate in Al-Mg-Si alloy from the results of HRTEM image. Its lattice parameter calculated from the diffraction pattern was different from that to $\beta$; phase and type-A precipitate in Al-Mg-Si alloy.

\section{Reference}

[1] K. Matsuda, Y. Sakaguchi, Y. Miyata et al., J. Mater. Sci., 35(2000) 179-189.

[2] M. H. Jacobs, Phil. Mag., 26(1961-62) 57. 
[3] J. P. Lynch, L. M. Brown and M. H. Jacobs, Acta. Metall.,30(1982) 1389

[4] H. Suzuki, M. Kanno and G. Itoh, J. Japan. Inst. Light. Met., 31(1981) 232-239

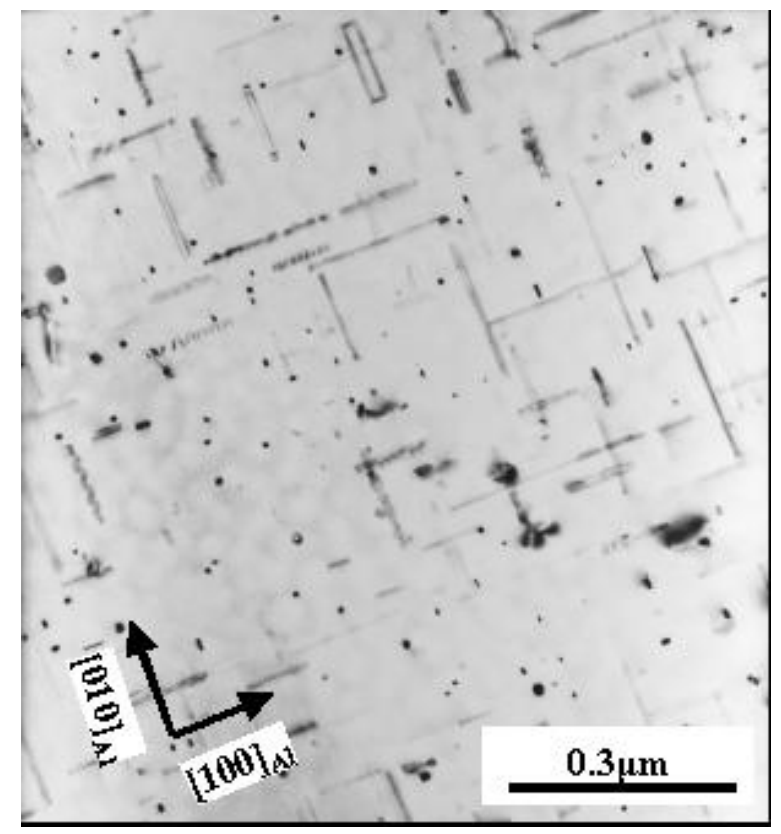

Fig.1 TEM image for Al-1.0mass $\% \mathrm{Mg}_{2} \mathrm{Ge}$ alloy aged at $523 \mathrm{~K}$ for $12 \mathrm{ks}$

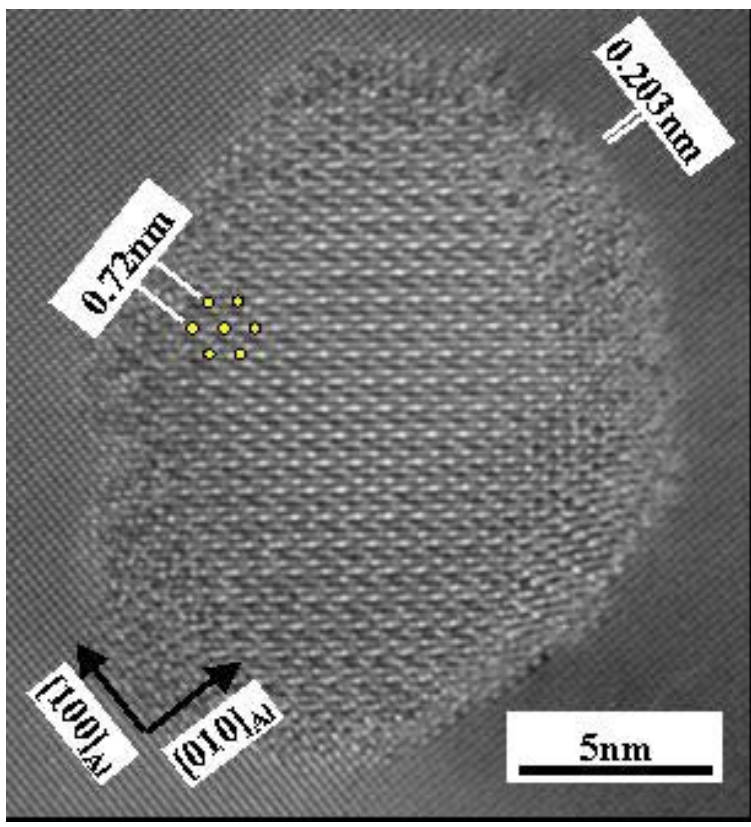

Fig.2 High resolution image of cross-section of the rod-shaped precipitate in $\mathrm{Al}-1.0 \mathrm{mass} \% \mathrm{Mg}_{2} \mathrm{Ge}$ alloy aged at $523 \mathrm{~K}$ for $600 \mathrm{ks}$.

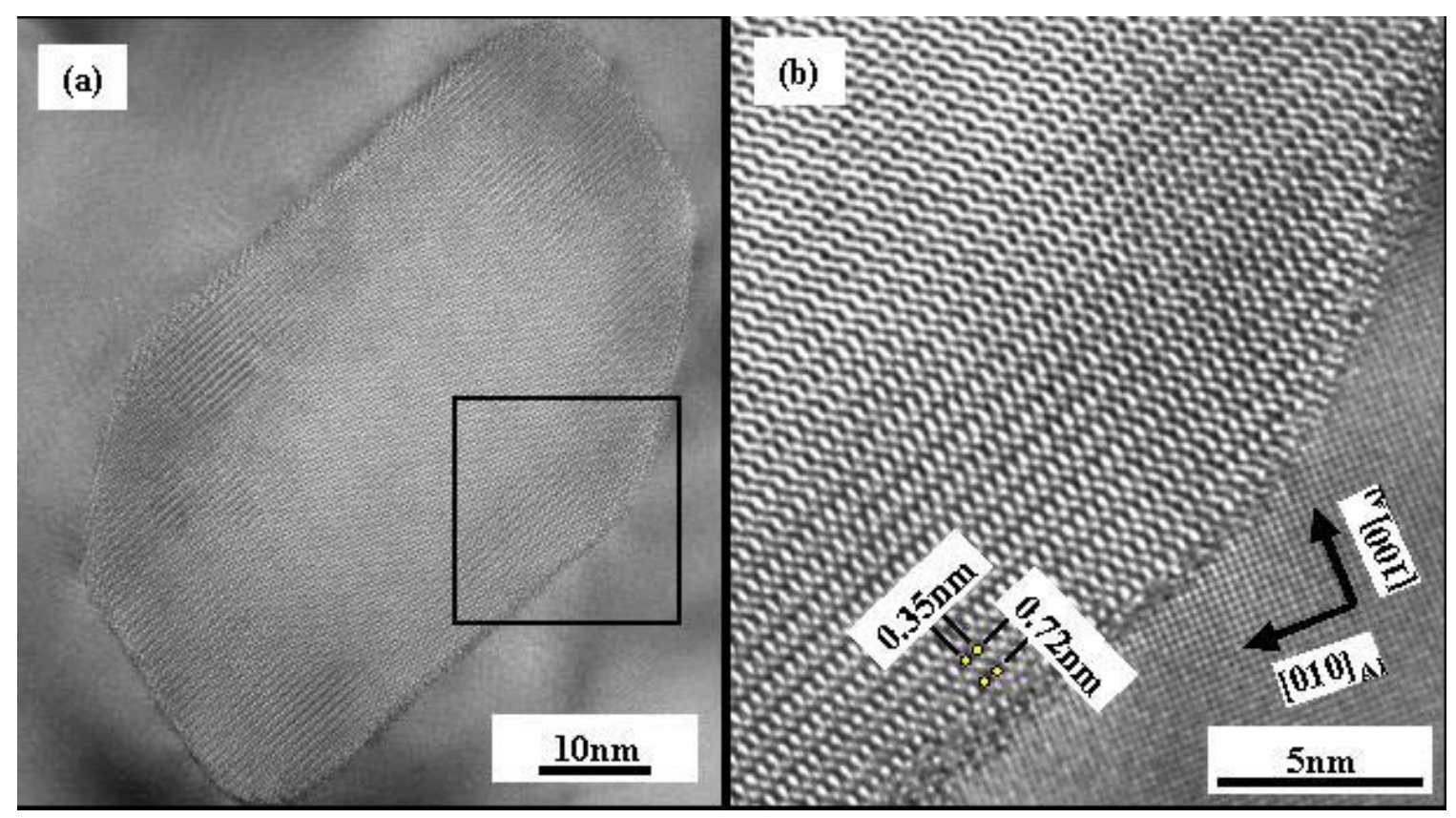

Fig.3 (a) High resolution image of cross-section of the coarse rod-shaped precipitate in $\mathrm{Al}-1.0 \mathrm{mass} \% \mathrm{Mg}_{2} \mathrm{Ge}$ alloy aged at $523 \mathrm{~K}$ for $600 \mathrm{ks}$. (b) Magnify from square region. 